\title{
Repercussões da inclusão escolar sobre o cotidiano de crianças com deficiência: um estudo a partir do relato das famílias*
}

\section{Repercussions of scholar inclusion on quotidian of children with special needs: a study initiated from families account}

\author{
Camila Costabile ${ }^{1}$, Maria Inês Britto Brunello ${ }^{2}$
}

\begin{abstract}
COSTABILE, C.; BRUNELLO, M. I. B. Repercussões da inclusão escolar sobre o cotidiano de crianças com deficiência: um estudo a partir do relato das famílias. Rev. Ter. Ocup. Univ. São Paulo, v. 16, n. 3 , p. 124-130, set./dez., 2005.

RESUMO: Na cidade de São Paulo, principalmente na rede pública municipal, tem-se optado em incluir crianças com deficiência em salas regulares de ensino, buscando garantir a equidade de direitos para todos. Partindo desse princípio, objetivou-se estudar e refletir, qualitativamente, os impactos da educação inclusiva na vida cotidiana das crianças com deficiência, a partir de entrevistas abertas com as famílias de crianças com deficiência mental e/ou distúrbios globais do desenvolvimento inseridas em classes regulares das escolas públicas, contribuindo com o desenvolvimento de avaliações sobre as repercussões da inclusão escolar na vida dessas crianças, promovendo reflexões, estimulando novas ações e trabalhos na área.
\end{abstract}

DESCRITORES: Terapia Ocupacional. Crianças portadoras de deficiência. Família. Avaliação educacional. Educação primária. Critérios de administração escolar.

\section{INTRODUÇÃO}

$\mathrm{N}$

o campo da educação, os terapeutas ocupacionais vêm atuando junto às esco las, propondo novas reflexões e ações que busquem facilitar a inclusão de pessoas com deficiência nas classes regulares do ensino.
A exclusão escolar é um fenômeno bastante antigo, como afirmam Silva et al. (2002), uma vez que nos espaços sócio-educacionais os indivíduos sempre foram organizados pela lógica da homogeneidade. Como lembra Ghirardi (2000), na prática o sistema educacional é classificatório e

\footnotetext{
* Pesquisa realizada como Iniciação Científica financiada pela FAPESP.

${ }^{1}$ Pesquisadora e aluna do curso de Terapia Ocupacional da Faculdade de Medicina da Universidade de São Paulo.

${ }^{2}$ Orientadora da pesquisa, docente do curso de Terapia Ocupacional da Faculdade de Medicina da Universidade de São Paulo.

Endereço para correspondencia:
} 
tem sido historicamente mais responsável por promover a exclusão social do que propriamente fomentar a inclusão. Os indivíduos, que por motivos diversos, são considerados desviantes da normalidade pelos padrões da sociedade, sempre encontraram obstáculos para conviver com o seu grupo social.

Nas décadas de 1950 e 1960 começam a ser criadas as escolas especiais e, mais tarde, as classes especiais dentro da escola comum. Mas é somente nos anos de 1970 que se observa uma crescente preocupação com a integração de pessoas com deficiência. Porém, ainda permanece a idéia de que é o aluno que deve adaptar-se ao sistema (OLIVETO, 1999) e que o fracasso escolar esta vinculado à deficiência, não sendo questionada a qualidade do ensino. A educação de alunos com deficiência ainda não é vista como parte e problemática da educação comum, como descreve Jurdi (2004).

A partir de 1980 pode-se observar uma série de movimentos que buscam a real inclusão das pessoas com deficiência nas escolas regulares. Várias leis foram promulgadas para defender os direitos de equidade para aqueles que viviam em situação de exclusão social. Um marco importante foi a Conferência Mundial de Jomtein, realizada em 1990, que defendeu a “educação para todos". E em 1994, a UNESCO e o Governo da Espanha organizam a Conferência de Salamanca, na qual foi firmada a Declaração de Salamanca, que propõe que "as escolas devem acolher todas as crianças independentemente de suas condições físicas, sociais, emocionais, de linguagem ou outras". No Brasil o referencial para a Educação para Todos recebeu a denominação de Educação Inclusiva (MAZZOTTA; SOUZA, 2000, p. 98-99).

Segundo Santos (2000), no Brasil, uma série de leis federais, estaduais e municipais foi formulada para efetuar o compromisso assumido na Declaração de Salamanca. Entre essas formulações está a Lei de Diretrizes e Bases da Educação Nacional (LDB), de 1996 que busca promover o direito da infância e da adolescência em relação à educação, apontando para a importância do atendimento do aluno com deficiência preferencialmente na rede regular de ensino (BARTALOTTI; CARLO, 2001).

Assim, a partir dessas mudanças, muito tem se realizado para que esses decretos sejam colocados em prática, apesar das dificuldades e entraves ainda encontrados, sendo necessário constantes avaliações dos trabalhos que vêm sendo feitos no sentido de buscar a inclusão das pessoas com deficiência.

Nesse sentido, esta pesquisa buscou contribuir com o estudo dos impactos da educação inclusiva na vida cotidiana das crianças com deficiência.

\section{MÉTODOSE TÉCNICAS}

Para a realização da pesquisa foram entrevistadas quinze famílias de crianças com deficiência mental e/ou distúrbios de desenvolvimento que estivessem freqüentando a escola regular desde a pré-escola até a $4^{\mathrm{a}}$ série do ensino fundamental. As entrevistas foram realizadas na casa de cada uma delas ou no próprio local de atendimento enquanto seus filhos estavam sendo acompanhados na terapia, sendo que em sua maioria foram as mães que forneceram as informações devido a facilidade de horários e, por estarem em contato próximo com seus filhos, puderam transmitir dados fundamentais para a realização da pesquisa. Essas famílias foram indicadas com o auxílio do Laboratório de Estudos sobre Deficiência e Cotidiano do Curso de Terapia Ocupacional da USP.

A entrevista aberta e não estruturada foi o instrumento utilizado para a coleta dos dados por possibilitarem uma discussão posterior mais enriquecedora (HAGUETTE, 1992; VIEIRA; HOSSNE, 2001).

Durante a realização das entrevistas, foi necessário lidar com algumas intercorrências como a não permissão do uso de gravador ficando a encargo do pesquisador anotar o maior número de informações sem perder a neutralidade dos dados e a dificuldade de encontrar horários nos quais as famílias estivessem disponíveis. Em alguns casos foi necessário um segundo encontro, porém observou-se que este não foi fundamental para a obtenção de maiores informações, pois as famílias geralmente repetiam o que já tinham falado ou apenas acrescentavam alguns detalhes antes não lembrados.

Foi elaborado um roteiro a fim de orientar as entrevistas que contemplou dados sobre: tempo que a criança freqüenta a escola, motivos pela escolha da classe regular e expectativas em relação a participação de seus filhos na escola, dificuldades encontradas na matrícula, adaptação das crianças, contatos das famílias com a escola, comentários da escola sobre o desenvolvimento das crianças e mudanças percebidas pelas mães nas atividades cotidianas das crianças após o ingresso nas classes regulares de ensino.

Foram selecionados temas comuns a todas as entrevistas a partir dos quais foi feita a análise de conteúdo: comentários sobre o dia-a-dia da criança, freqüência em classe ou escola especial anterior à classe regular, motivos que facilitaram a escolha pela classe regular, facilidades e entraves encontrados no processo de matrícula e durante a permanência da criança na escola, avaliação das famílias quanto a atenção oferecida pela escola à criança, comentários da escola em relação a participação dessas crianças na classe regular e avaliação das famílias no que diz respeito as mudanças ocorridas no dia-a-dia de seus filhos. 


\section{Análise das Entrevistas}

Com as entrevistas, pôde-se notar que as famílias tiveram a oportunidade de refletir sobre o desenvolvimento das crianças e de observar pontos positivos de seu amadurecimento, além de pararem para pensar sobre a escola, questionando-a e, na maior parte das vezes, buscando propostas de alterações no sistema educacional para uma melhoria deste.

Para a análise das entrevistas foram selecionados temas comuns trazidos pelas mães que contribuíram para compreender e refletir sobre as possíveis mudanças na vida das crianças com deficiências ocorridas a partir do momento que passam a freqüentar classes regulares de ensino.

\section{Da educação especial para a classe regular}

Analisando a participação das crianças em classes especiais ou regulares, constatou-se que quatro crianças já haviam freqüentado escola ou classe especial e onze foram direto para a escola regular.

As famílias, cujas crianças já estudaram em escola ou classe especial, fizeram algumas críticas a esta proposta, como ilustra a seguinte fala:

"Antes ela estava em uma escolinha especial, só que eu via que não estava dando certo né... porque eu vi que ela estava acompanhando o mesmo roteiro das outras crianças... Ela estava imitando como as crianças estavam falando. Estava atrapalhando o desenvolvimento e o crescimento dela... A P. não tinha contato com crianças, só com as crianças especiais e estava indo no mesmo caminho delas."

Nas falas das famílias fica evidente algumas idéias pré-concebidas que estas tinham de seus filhos como a incapacidade de permanência na escola devido a sua deficiência e dificuldade que poderiam encontrar em conviver junto às outras crianças, como mostra o depoimento:

"Pensei que ia ser uma coisa do outro mundo, muito difícil ela numa escola com outras crianças, mas aí eu fui e coloquei e falei assim: vou experimentar e, se der certo, eu continuo e se não der, ela não vai para a escola."

Mesmo com tal imagem, as famílias apostaram nas crianças e obtiveram resultados satisfatórios, trazendo mudanças do olhar sobre as potencialidades de seus filhos e passam a acreditar que todo processo de inclusão pode gerar mudanças sociais:

"só vai haver uma conscientização se as pessoas conviverem com a diferença." pública?

Por que a escolha por uma escola regular da rede

Durante as entrevistas, pôde-se concluir que as razões e as expectativas que levaram as famílias a escolherem escolas públicas regulares para as crianças foram variadas, mas grande parte dos entrevistados concordaram que os motivos principais passavam pela possibilidade de convivência com outras crianças e de um aprendizado diversificado, bem como com a possibilidade das crianças serem alfabetizadas. Os outros motivos e expectativas são: desenvolvimento e amadurecimento, maior independência, maior aceitação às regras sociais. A questão financeira foi um fator importante na escolha das escolas. E pode-se observar que a orientação de profissionais da saúde e da educação foi importante para o encaminhamento dessas crianças para classes regulares.

A seguinte fala ilustra essa questão:

"Mais para frente quero que ele leia e escreva, mas agora o importante para mim é a socialização mesmo."

Percebe-se, assim, que as famílias, geralmente, optam por escolas públicas regulares pensando no projeto e no objetivo geral da escola que são a alfabetização e a ampliação da socialização, isto é, poder conviver com outras crianças que não sejam apenas aquelas com deficiência.

Chama a atenção a expectativa que as famílias têm de buscar a normalidade das crianças por meio da escola regular, aparecendo em quase todas as entrevistas falas como:

"Tenho esperança de que um dia meu filho seja normal dentro do possível."

Entraves e facilidades durante o processo de inclusão na classe regular

Em relação à matrícula, apenas duas famílias encontraram dificuldades, pois as escolas alegaram não estarem preparadas para lidar com uma criança com deficiência, não aceitando a criança como aluna. As outras treze famílias conseguiram matricular as crianças sem grandes problemas.

Este dado mostra que a legislação que afirma que o aluno com deficiência deve ser atendido preferencialmente na rede regular de ensino (Lei de Diretrizes e Bases da Educação Nacional de 1996) vem fortalecer a aceitação da convivência entre as diferenças e o reconhecimento das potencialidades de cada sujeito.

Porém, muitas famílias relatam os problemas encontrados depois da matrícula, como a falta de profissionais especializados, a falta de tolerância das outras crianças que apresentam atitudes excludentes e estigmatizantes, 
dificultando a socialização com os colegas, a falta de adaptação da escola às dificuldades da criança, a dificuldade em relação ao aprendizado, necessitando, muitas vezes, de programas e currículos adaptados.

Percebe-se que a legislação facilita a entrada das crianças com deficiência nas escolas regulares da rede pública de ensino, mas, muitas vezes, não garante de fato a inclusão escolar, pois faltam condições satisfatórias ao aprendizado dessas crianças, justificado pelo número elevado de alunos por sala de aula, a falta de apoio dos professores, a pouca formação da equipe educacional, a falta de preparo das escolas e de políticas que apoiem estes trabalhos.

\section{Contato família-escola}

Todas as famílias afirmaram estar sempre em contato com a escola, preocupando-se com o processo de aprendizado e com o comportamento da criança. Entre esses contatos, as formas citadas foram: reuniões com professores e coordenação, conversas com a professora ou diretora no momento de levar e buscar a criança na escola e por telefone.

\section{Comentários da escola sobre o desenvolvimento da criança trazidos pelas famílias}

Em relação aos comentários da escola sobre o desenvolvimento da criança, observa-se que, essas instituições percebem e comentam os progressos nas áreas motora, cognitiva e social de muitas delas. Relatam maior socialização, melhor capacidade de aprendizado, como também mais obediência, respeito às regras e maior responsabilidade. Porém, enfatizam, ainda, a dificuldade de aprendizado pedagógico, afirmando que o "processo é lento", e os problemas enfrentados diante dos comportamentos que fogem às normas da escola, tais como não ficar parado, não prestar atenção, sair da sala de aula constantemente, ser agressivo ou então não se comunicar verbalmente. Muitos professores explicitam a dificuldade de ensinar a 40 alunos e mais aqueles que não conseguem acompanhar as informações pedagógicas.

\section{Mudanças percebidas no cotidiano das crianças pe- las famílias}

As áreas onde mais se notou alterações foram: maior socialização; melhora na comunicação; mais independência nas Atividades de Vida Diária-AVD’s (comer, vestir-se, tomar banho, higiene pessoal); mais disciplina e compreensão de regras sociais e diversificação das brincadeiras. As outras, menos citadas, porém não com menor importância, foram: mais responsabilidade; melhora na coordenação motora; mais iniciativa; menos agitação; maior participação; criação de rotina; melhora na compreensão verbal e gestual; amadurecimento; aprender a se defender; maior interesse em ler, pintar e rabiscar; mais independência e autonomia; menos agressividade e imitação dos colegas. Apenas uma família destacou um ponto negativo: a criança passou a ser mais desobediente e rebelde em casa.

Os comentários das famílias nas entrevistas podem ilustrar essas mudanças:

"Ela está falando mais e mostrando o caderno para eu ver quando tem bilhete. Agora já chuta a bola, tá correndo agora... chama as crianças para brincar com ela... Na escola, aprendeu os horários de fazer as coisas, de ir no banheiro, de escovar os dentes."

"Se esforça mais para ser entendido."

Cabe ressaltar que algumas famílias afirmaram que a escola não foi responsável sozinha por essas mudanças percebidas no cotidiano da criança, pois os tratamentos e as terapias interferiram e auxiliaram bastante nesse processo, mostrando que um espaço único não é propiciador de mudanças nas ações das crianças.

\section{público \\ Avaliação das famílias sobre o sistema educacional}

Muitas famílias fizeram algumas críticas às escolas e somente quatro delas afirmaram não ter nenhuma sugestão ou reclamação no momento. As críticas foram bastante interessantes, pois a maior parte dos entrevistados disse que as crianças com algum tipo de comprometimento mental ou psíquico têm dificuldade de atenção dentro da sala de aula e que devido ao grande número de alunos para uma professora e também por falta de uma auxiliar de classe essas dificuldades aumentam. Reconhecem algumas falhas no investimento do sistema educacional como um todo, como explicitado por uma das famílias. Outros comentários a respeito do tema também podem ser incluídos aqui: dificuldades da escola em adaptar currículos e métodos de ensino; pouco apoio para a formação dos professores em atender essas crianças e o medo de que a aprovação automática não seja benéfica.

O depoimento abaixo explicita essas questões:

"As classes deveriam ser com menos alunos; os professores mais especializados para poderem auxiliar no processo, trabalhando em conjunto com a 
Coordenadoria da Educação; mais especialistas auxiliando o professor na sala de aula e reuniões periódicas entre pais, professores e profissionais especializados para discutir, aprender e auxiliar neste processo de inclusão."

Mesmo com essas críticas, sete famílias afirmaram que a escola tem correspondido às suas expectativas quanto à socialização e convivência de seus filhos. Todos os entrevistados falaram sobre a importância da escola como um espaço para a criança aprender a viver em grupo pela convivência, pela possibilidade de mais independência e maior disciplina.

O que se pode observar é que mesmo com as dificuldades encontradas no dia-a-dia escolar essas crianças vêm demonstrando progressos e mudanças no seu crescimento. $O$ contato com o outro, a vivência de situações novas, bem como com diferentes regras sociais propiciam melhor desenvolvimento à criança. Além disso, os professores e outros profissionais envolvidos no processo têm buscado recursos próprios (e muitas vezes bastante criativos) para ensinar essas crianças, contribuindo para o seu crescimento.

\section{Discussão sobre os progressos no desenvolvimento relatados nas entrevistas}

A partir das entrevistas, foi possível analisar os progressos das crianças em diferentes áreas do desenvolvimento e do aprendizado (conceito este que, segundo Vygotsky, é definido como o processo de aquisição de informações, atitudes e habilidades gerado pela interação social e com o ambiente), demonstrando a importância e os reflexos da participação delas na escola regular.

a) ampliação do repertório das atividades lúdicas

"Depois que ela entrou na escola, ela brinca mais... que nem boneca ela não se interessava, em dar banho no neném... Hoje ela se interessa, ela brinca... a convivência com as outras crianças ajudou muito."

b) a socialização e o contato com o outro

"Tinha dificuldades para estabelecer contato e brincar em grupo. Hoje se relaciona bem melhor e observa muito o que acontece à sua volta para tentar fazer igual."

c) independência e autonomia nas atividades de vida diária

"ela come sozinha na escola, vai ao banheiro sozinha na escola."

d) compreensão de novas regras sociais e mudança de atitude frente ao outro “...não morde mais... não bate mais..."

"Antes M. era tímida e pacata. Hoje... já gosta, já quer, já escolhe, já deseja."

e) conquistas na área pedagógica

"já está começando a escrever o A."

f) ampliação da comunicação verbal e não verbal

"Ela passou a falar mais e chamar as pessoas depois da escola... está começando a desenvolver a fala."

Assim, a partir desses depoimentos, se o aprendizado é adquirir por meio do social e do ambiente elementos para o desenvolvimento, pode-se afirmar que essas crianças têm adquirido novos conhecimentos, porque o aprender não é somente, como afirmam Kupfer e Petri (2000), ler e escrever, mas se apropriar de todos os elementos que propiciam o desenvolvimento, o crescimento, a capacidade de socialização, de comunicação, de trocas com o meio social e autonomia.

\section{Reflexões sobre propostas para uma melhor inclu- são escolar}

Hoje, a organização do ensino público demonstra algumas dificuldades no processo de inclusão escolar, tanto em relação à própria infra-estrutura das escolas como também à formação dos professores.

Assim, algumas questões sobre o processo de inclusão foram pensadas, como a reorganização dos espaços físicos da sala de aula; utilização de técnicas mais individualizadas de ensino; diminuição do número de alunos por sala de aula; contratação de auxiliares de classe e professores; formação contínua de professores; elaboração de projetos pedagógicos interdisciplinares; aprendizado cooperativo e, por fim, investimento maciço em educação.

A escola precisa se fortalecer cada vez mais como um espaço de criatividade, promovendo o desenvolvimento físico, cognitivo, afetivo e moral de todos os alunos, ao mesmo tempo em que deve facilitar a inclusão na sociedade como membros ativos.

As crianças com deficiência devem ser educadas com metas iguais às propostas para as crianças sem deficiência, relacionando-se com sua comunidade para alcançar uma efetiva inclusão social. Assim, o currículo deve servir como um roteiro de trabalho para os professores e tal roteiro deve ser flexível e modificado de acordo com as necessidades individuais.

Dentro da escola, o professor é o responsável mais direto pela evolução escolar das crianças com deficiência 
e, por isso a necessidade de oferecer condições básicas essenciais a esses profissionais, assegurando formação contínua e espaços de reflexão de suas práticas.

É necessária a adequação das práticas pedagógicas às diversidades dos alunos. Estes profissionais devem estar convictos que as crianças com deficiência são capazes de construir seu próprio conhecimento na medida em que interagem com o mundo dos objetos e das outras pessoas.

Todos os professores, funcionários e família devem estar incluídos no processo de inclusão escolar. Além disso, a escola deve sempre estar em sintonia com outras instituições sociais, de forma que as necessidades dos alunos com deficiência, sejam atendidas e trabalhadas.

Todas as ações para a inclusão devem ser constantemente reavaliadas no intuito de se construir uma escola que consiga efetivar as políticas direcionadas para a inclusão dos alunos com deficiência. Assim, a reorganização da escola vai além de uma reformulação do espaço físico, do conteúdo programático e de maior preparação dos professores, pois dessa forma as ações se voltariam somente para os elementos e fatores intra-escolares, deixando esquecidos os contextos sociais, econômicos e culturais em que se inserem. É necessário, portanto, uma política eficaz que leve em conta o contexto escolar atual e que proporcione uma revolução no ideário político-ideológico de homogeneização do ensino.

\section{CONCLUSÃO}

A inclusão é um processo dinâmico, o qual depende de constantes avaliações, reflexões, discussões com as práticas e vivências, para que se torne realmente efetivo. Assim, como qualquer proposta inovadora, ela não se efe- tiva apenas por decreto, mas por ações que possibilitem sua viabilidade e pela disposição das pessoas em aceitar a diversidade como condição inerente à sociedade. Foi constatado que, apesar da legislação existente, as escolas devem estar mais preparadas para receber o aluno com deficiência, a fim de que a inclusão não se torne, na verdade, uma forma de exclusão dentro da própria escola.

Com a inclusão escolar, à medida que o aluno com deficiência convive com crianças consideradas normais e com elas participa de determinadas experiências, aprende a conviver com suas próprias deficiências dentro das condições normais de vida. Nota-se, assim, um salto no que diz respeito à ampliação da sociabilidade, da autonomia, da independência da comunicação e do desenvolvimento global.

Na vivência cotidiana da escola, há a oportunidade de aprender as regras do convívio social e experimentar novas atividades, estabelecer relações com diferentes pessoas, espaço, tempo e objetos. Estas relações contribuem para o desenvolvimento e aprendizagem, colocando em funcionamento os aspectos afetivos, sensoriais, motores e cognitivos.

Além disso, com a inclusão nas classes regulares de ensino, as crianças têm a oportunidade de serem vistas e tratadas como sujeitos capazes de construir seu conhecimento, enriquecendo suas experiências, bem como a de toda a equipe pedagógica. A mútua convivência possibilita a aceitação das diferenças, dificultando a formação de idéias preconceituosas sobre a deficiência.

A escola inclusiva, portanto, contribui para que as crianças desenvolvam suas potencialidades e, respeitando as individualidades, contribui para uma melhora da qualidade de vida e favorece o repensar sobre práticas que excluem as pessoas com deficiência.

COSTABILE, C.; BRUNELlO, M. I. B. Repercussions of scholar inclusion on quotidian of children with special needs: a study initiated from families account. Rev. Ter. Ocup. Univ. São Paulo, v. 16, n. 3, p. 124-130, set./dez., 2005.

\begin{abstract}
At São Paulo City, mainly in the public municipal net, special needs children have been included in mainstream school rooms, looking for to guarantee the universal equity for all people. According to this concept, the main purpose of this research was to study and to consider, on the qualitative way, the impacts of inclusive education on daily life children with special needs by interviewing families with mental deficiency and developmental disturbance children included in rooms of mainstream public schools, by making contributions to develop tests about the repercussions of inclusion on children's life, by promoting reflections and encouraging new actions and studies in this area.
\end{abstract}

KEY WORDS: Occupacional Therapy. Disabled children. Family. Educational measurement. Education, primary and secondary. School admission criteria. 


\section{REFERÊNCIAS}

BARTALOTTI, C.; CARLO, M. M. R. P. Terapia ocupacional e os processos socioeducacionais. In: BARTALOTTI, C.; CARLO, M. M. R. P. (Orgs.). Terapia ocupacional no Brasil, fundamentos e perspectivas. São Paulo: Plexus, 2001. Cap. 5, p. 99-116.

BRUNELLO, M. I. B. Ser lúdico: promovendo a qualidade de vida na infância com deficiência. 2001. Tese (Doutorado) Instituto de Psicologia, Universidade de São Paulo, São Paulo, 2001. p. 21-28, 74-102.

CARLO, M. R. P. C. Vygotsky e o desenvolvimento humano comprometido pela deficiência. In: CARLO, M. M. R. P. Se a casa fosse nossa: instituições e processos de imaginação na educação especial. São Paulo: Plexus, 2001. Cap. 3, p. 65-83.

GHIRARD, M. I. G. Educação inclusiva, processos psicológicos e a terapia ocupacional. Rev. Ter. Ocup. Univ. São Paulo, v. 11, n. 1, p. $13-6,2000$.

GIACON, B. D. M. A educação necessária à inclusão. Rev. Mundo Saúde, São Paulo, v. 26, n. 3, p.413-416, 2002.

HAGUETTE, T. M. F. Metodologias qualitativas na sociologia. 2a ed. Petrópolis: Editora Vozes, 1992. p. 75-92.

IDE, S. M. O itinerário de uma experiência: a construção do conhecimento de crianças deficientes mentais portadores de síndrome de Down e sua interação no contexto escolar comum. 272f. 1993. Tese (Livre Docência) - Faculdade de Educação, Universidade de São Paulo, São Paulo, 1993.

Recebido para publicação: 05/08/2005

Aceito para publicação: 25/09/2005
JURDI, A. P. S. O processo de inclusão escolar do aluno com deficiência mental: a atuação da Terapia Ocupacional. 146f. 2004. Dissertação (Mestrado) - Instituto de Psicologia, Universidade de São Paulo, São Paulo, 2004.

KOHL, M. de O. Vygotsky: aprendizado e desenvolvimento Um processo sócio-histórico. 4a ed. São Paulo: Editora Scipione, 1997.

KUPFER, M. C. M.; PETRI, R. Por que ensinar a quem não aprende? Estilos da Clínica, n. 9, p. 109-117, 2000.

MAZZOTTA, M. J. S.; SOUZA, S. M. Z. Inclusão escolar e educação especial: considerações sobre a política educacional brasileira. Estilos da Clínica, n. 9, p. 96-108, 2000.

OLIVETO, J.; MANZINI, E. T. (Org.). Dificuldades dos professores de pré-escola no trabalho de integração de alunos com deficiência. 1999. (Trabalho Final) - Curso de Especialização em Educação Especial, UNESP, Marília, 1999. p. 26-84.

SANTOS, M. P. dos. Educação inclusiva e a declaração de Salamanca: consequiências ao sistema educacional brasileiro. Rev. Integração, São Paulo, n. 22, p. 34-40, 2000.

SILVA, I. M. da; BIANCHI, S. V.; SIMIONATO, S. V. A prática inclusiva numa escola pública. Rev. Mundo da Saúde, São Paulo, v. 26, n. 3, p. 407-412, 2002.

VIEIRA, S.; HOSSNE, W. S. Metodologia científica para a área da saúde. Rio de Janeiro: Campus, 2001. p. 27-47. 